\title{
Environmental Impacts of Short Rotation Coppice (SRC) Grown for Biomass on Agricultural Land
}

\author{
Martin Weih • Ioannis Dimitriou
}

Published online: 26 June 2012

(C) Springer Science+Business Media, LLC 2012

This issue of BioEnergy Research highlights the activities within a European Union research project funded by ERANET Bioenergy, "Reducing environmental impact of SRC through evidence-based integrated decision support tools" (RATING-SRC). The project goal was to provide scientific evidence for evaluating the impacts - positive and negativeof short rotation coppice (SRC) plantations on soil, water, biodiversity, and landscape issues and also to propose ways to mitigate the negative and increase the positive impacts.

Commercial SRC plantations are currently grown at limited scale in some countries (e.g., Sweden), but the area of SRC plantations has to increase dramatically in the future if they are to contribute significantly to the replacement of fossil energy sources. Thus, a rapid increase of agricultural land dedicated to SRC with willow (Salix spp.) or poplar (Populus spp.) for production of biomass for heat and/or electricity is projected in the short-term in many regions of the world. A large-scale shift from "conventional" arable crops to SRC will have implications on a range of environmental issues, and largescale implementation of those crops for bio-energy purpose makes sense only if they prove to reduce negative effects on the environment, especially when compared with other alternatives for reduction of fossil energy sources. As a perennial crop, SRC differs from most arable crops in physical traits and management practices. Results so far imply many positive environmental benefits due to SRC implementation, but the effects that SRC will have on the environment depend on the existing or previous land use, the scale of planting and the management practices applied. In addition, SRC is a new

M. Weih $(\triangle) \cdot$ I. Dimitriou

Department of Crop Production Ecology,

Swedish University of Agricultural Sciences,

Box 7043, 750-07 Uppsala, Sweden

e-mail: martin.weih@slu.se production system for most regions in which it might be grown in future, and many uncertainties exist with respect to the environmental impacts of those plantations on soil, water, biodiversity, and landscape issues.

This special issue contains seven papers covering the topic areas of SRC effects on issues of water and soil (two papers by Dimitriou et al., Schmidt-Walter and Lamersdorf), biodiversity (Baum et al.), and the overall impact that these plantations may have on the environment and sustainability (Busch, Englund et al., Langeveld et al.). The paper on soil issues by Dimitriou et al. highlights the results for $\mathrm{pH}$, organic carbon $(\mathrm{C})$, and trace element concentrations in the soil of 14 long-term (10-20 years) commercial willow SRC fields in Sweden when compared with those in adjacent, conventionally managed arable soils. The paper on water issues by Dimitriou et al. reports the effects of SRC on water quality by determining differences in leaching of nitrogen and phosphorus to groundwater of 16 commercial SRC stands in Sweden compared to adjacent arable fields grown with "ordinary" crops. Schmidt-Walter and Lamersdorf describe effects on groundwater quality, specifically the potential effects of SRC grown under different management regimes on groundwater recharge. Based on flora inventories in eight landscapes located in two European regions (Germany and Sweden), the paper by Baum et al. focuses on the diversity of higher plants as an indicator of biodiversity in willow and poplar SRC, including various scales ranging from habitat to landscape level diversity. The contribution by Busch is an attempt to assess the impact of SRC on various landscape functions with the help of GIS-based tools. Englund et al. focus on the potential effects of sustainability requirements within the EU Renewable Energy Directive (RED) on different stakeholders along SRC bioenergy supply chains, assessing their usefulness in ensuring that SRC bioenergy is produced with 
sufficient consideration given to the RED-associated criteria. Langeveld et al. integrate much of the scientific evidence reported in the above contributions and propose a model for semiquantitative impact assessment regarding various environmental issues.

We would especially like to thank the various anonymous reviewers for their contributions to this special issue and the four guest editors who worked so efficiently and partly under tight deadlines to organize peer review of manuscripts for this special issue. The guest editors were: Professor Lena Gustafsson, Swedish University of Agricultural Sciences, Uppsala, Sweden; Dr. Angela Karp, Rothamsted Research, Harpenden, UK; Dr. Ronald S. Zalesny Jr., U.S. Forest Service, Northern Research Station, Rhinelander, WI; and Dr. Georg von Wühlisch, Johann Heinrich von Thünen Institute, Großhansdorf, Germany. 